\title{
Pathomorphological Studies on Hepatic Disorders in Sheep
}

\author{
H. J. Kiran*, G. M. Jayaramu, B. Kavitha Rani, S. S. Manjunatha and E. S. Satish \\ Department of Veterinary Pathology, Veterinary College, KVAFSU, Shivamogga, India \\ *Corresponding author
}

\section{A B S T R A C T}

\begin{tabular}{l} 
Ke y w or d s \\
$\begin{array}{l}\text { Liver, Disorders, } \\
\text { Sheep }\end{array}$ \\
Article Info \\
$\begin{array}{l}\text { Accepted: } \\
\text { 04 October } 2020 \\
\text { Available Online: } \\
\text { 10 November } 2020\end{array}$ \\
\hline
\end{tabular}

Most of the septicaemic diseases in small ruminants affect liver, as most of the blood pass through this organ. Major sources of etiologies/ afflictions are from pathogenic organisms, nutrition, xenobiotics or toxins whose effects are varied, which may be localized or generalized, cumulative or chronic, acute, sporadic or outbreaks etc. Liver is vulnerable to many parasitic infections and helminthic diseases such as Fasciolosis, Cysticercosis, Hydatidosis and Stilesia hepatica make liver unsuitable for human consumption due to condemnation upon meat inspection. A total of 110 sheep mortalities were necropsied and of which 105 livers showing abnormalities were noted. The most frequent lesions observed were congestion $(73.33 \%)$ followed by cell swelling $(23.81 \%)$, haemorrhage $(21.90 \%)$, hydropic degeneration $(18.09 \%)$, coagulative necrosis $(18.09 \%)$, acute focal hepatitis $(14.28 \%)$, fatty change $(8.57 \%)$, biliary hyperplasia $(6.67 \%)$, acute multifocal hepatitis $(5.71 \%)$, chronic hepatitis $(3.81 \%)$, thrombosis $(0.95 \%)$ and hepatic abscess $(0.95 \%)$ in liver.

\section{Introduction}

Sheep farming is one of the important agriculture based activities, practiced by a large section of farmers in developing countries like India, which plays an important role not only in income generation but also in improving the household nutrition. Government of India encourages farming of small ruminants towards achieving food security. India ranks third in the world with a sheep population of 75 million with an estimated annual meat production at 4 million tonnes and 47.9 million $\mathrm{kgs}$ of wool. Sheep farming contributes about 43,232 crores and 403 crores of Indian rupees through meat and wool respectively, to the national economy (FAOSTAT, 2014).

Numerous factors are responsible for economic losses in the sheep industry. Among them, problems related to health are of utmost importance. The small ruminant population in our country is frequently exposed to ravages of infectious diseases, which is of major constraint in sheep production.

Most of the septicaemic diseases in small ruminants affect liver as most of the blood pass through this organ. Major sources of etiologies/ affections are from pathogenic organisms, nutrition, xenobiotics or toxins 
whose effects are varied, which may be localized or generalized, cumulative or chronic, acute, sporadic or outbreaks, etc.Liver is vulnerable to many parasitic infections and helminthic diseases such as Fasciolosis, Cysticercosis, Hydatidosis and Stilesia hepatica make liver unsuitable for human consumption due to condemnation upon meat inspection.

In addition, liver abscesses caused by bacterial septicaemia represent another major reason for meat condemnation (Tehrani et al., 2012). In these geographical areas, sheep husbandries mainly comprise nomadic practices and hence, etiologies responsible for sheep mortalities are often unknown or obscure.

\section{Materials and Methods}

Out of 110, 105 samples from sheep showing liver lesions were collected regardless of the age, sex and breed.Carcasses of slaughtered and necropsied sheep were examined. A detailed gross examination of liver with respect to size, color and consistency were collected.

Representative tissue samples fixed in $10 \%$ neutral buffered formalin were processed by routine paraffin-embedding technique and 4-5 $\mu \mathrm{m}$ thick sections were stained by routine Haematoxylin and Eosin (H\&E) for detailed histopathological studies. In selected cases, adjacent sections of tissue samples were stained using special staining techniques which included Gram's staining for bacteria and Masson's trichrome for collagen (Luna, 1968).

The stained sections will be examined under bright field microscope and documented. The results of gross and histopathology will be analysed and interpreted.

\section{Histopathological classification of lesions in liver}

The lesions recorded in the liver were classified as described earlier based on inflammation and the principal constituent of the exudates. These include vascular/ circulatory changes, degenerative and necrotic changes, inflammatory changes, growth adaptive changes / responses (Mason and Madden, 2007).

\section{Results and Discussion}

Based on gross and histopathological features, hepatic disorders were grouped as circulatory changes, degenerative and necrotic changes, inflammatory changes and others. In the present study, 105 cases $(95.45 \%)$ of liver showed pathologies were recorded.

\section{Circulatory disturbances}

In the present study, circulatory disturbances in liver comprised of congestion (73.33\%), haemorrhages $(21.90 \%)$ and thrombosis $(0.95 \%)$. Bhavyapriyanka (2017) recorded a lower occurrence of 2.24 per cent of congestion whereas Khan et al., (2015) recorded a higher occurrence of $47.36 \mathrm{per}$ cent of haemorrhages. Congestion was found to occur frequently in sheep belonging to nomadic herds which could be attributed exposure to various toxic agents through ingestion of environmental toxicants or plants during migratory period. Chronic venous congestion of liver occurs commonly due to stagnation of blood within the central vein and adjacent sinusoids with subsequent fatty degeneration of peripheral hepatocytes because of hypoxia. Hepatic congestion is reported to occur due to either infectious causes (Omotainse and Anosa, 2009) or noninfectious causes (Ozmaie et al., 2013). Liver with congestion appeared dark red grossly and blood oozed out freely from the cut surface. Microscopically, congestion of 
vascular and sinusoids along with hydropic degeneration of hepatocytes, fatty changes, haemorrhages and thrombosis were noticed (Fig. $1 \& 4$ ).

Occurrence of haemorrhage might be due to various systemic disorders like cardiac and pulmonary lesions, plant poisoning or hemorrhagic septicemia (Ozmaie et al., 2013; Verma, 2014). Microscopically, either petechial or ecchymotic haemorrhages were observed in this study which revealed focal areas of haemorrhages (Fig. 1) which is in conformity with the findings of Arafat et al., (2015).

Thrombosis could be seen in severe congestion, bacterial or parasitic infections (Fig. 1). Along with thrombosis, focal hepatitis, coagulative necrosis with congested central and portal vessels were also noticed, which is in argument with findings of Kumar et al., (2013).

\section{Degenerative and necrotic changes}

In the present study, degenerative changes comprised of hepatic cell swelling (23.81\%), hydropic degeneration (18.09\%), fatty changes $(8.57 \%)$ and coagulative necrosis (18.09\%). Khan et al., (2015) recorded a higher occurrence of hepatic cell swelling with 52.63 per cent. Hassanein et al., (2017) recorded a lower occurrence of hydropic degeneration at 0.002 per cent. Sarkar (1998) recorded a similar occurrence of fatty changes at 8.5 per cent of fatty changes.

Microscopically, hepatic cell swelling revealed cytoplasmic granulation and reduced sinusoidal spaces were seen. In some cases, the adjacent areas showed hydropic degeneration and necrotic changes (Fig. 2). The recorded observations are well in accordance with those described by Tafti et al., (2008).
Microscopically, the hepatocytes were enlarged with the presence of small multiple clear or pale vacuoles, within the cytoplasm and a normal nucleus in central position which appeared like 'bull eye' (Fig. 2), which is well in accordance with those described by Hassanein et al., (2017). Hydropic degeneration could be seen after exposure of liver to various toxin, hypoxia and anaemia, which is in agreement with the reports of earlier workers (Thannon, 2018).

In the present study, fatty change was observed as associated lesions in conditionof plant poisoning and cardiac cirrhosis. Fatty change was reported to be a common finding in cases of toxemia, anemia and hypoxia (Thannon, 2018). Grossly, fatty livers were enlarged with rounded borders, the affected part being soft, greasy and yellow in color (Fig. 3). Microscopically, clear, round globules were noticed within the cytoplasm of hepatocytes (Fig. 4). Gross and microscopic observations are well in accordance with those described by Abed (2012) and Kumar et al., (2013). Fat accumulation is a sensitive response to hepatocellular injury and can occur in the absence of other obvious alteration in hepatic structure and function (Jubb et al, 2007).

Occurrence of coagulative necrosis in the present study could be due to Babesiosis or pregnancy toxaemia. Grossly, liver was dark reddish in color with necrotic patches. Microscopically, hepatocytes were homogenously pink in color with absence of nuclei (Fig. 8). The recorded observations were similar to those described by Zangana and Aziz (2012), Thannon (2018) and Hamond et al., (2019).

\section{Inflammatory changes}

In the present study, inflammatory condition of liver comprised of acute hepatitis (20\%), 
chronic hepatitis $(3.81 \%)$ and hepatic abscess $(0.95 \%)$. Gezu and Addis (2014) recorded a similar occurrence of acute hepatitis at 19.8 per cent. Regassaet al., (2013) recorded a higher occurrence of chronic hepatitis 42.10per cent. Tehrani et al., (2012) recorded a higher occurrence hepatic abscess at $4.6 \mathrm{per}$ cent.

Microscopically, acute hepatitis showed marked congestion, focal necrosis and accumulation of neutrophils within sinusoids and in the parenchyma were the salient microscopic findings along with infiltration of inflammatory cells in the portal areas (Fig. 5 $\& 1$ ). The recorded observations are similar to those described by Al-Nassir (2014) and Hamond et al., (2019). In the present study, the occurrence of chronic hepatitis at $3.81 \mathrm{per}$ cent might be because of coccidiosis, hemorrhagic septicemia or plant poisoning. Arafat et al., (2015) reported cirrhosis as end stage of liver and occurs because of bacterial infection. Grossly, the liver was enlarged with a mottled surface, fibrosis and nodule formation. Microscopically, massive necrosis with atrophy, fibrosis and accumulation of mononuclear inflammatory cells such as lymphocytes, macrophages and plasma cells were seen (Fig. 6). These findings are in conformity with the findings of Dharvadiya et al., (2014).

Table.1 A comparison of histopathological conditions in liver of sheep mortalities

\begin{tabular}{|c|c|c|c|}
\hline SI. No. & Conditions & No. of cases & $\%(\mathrm{~N}=105)$ \\
\hline 1. & \multicolumn{3}{|l|}{ Circulatory disturbances } \\
\hline & Congestion & 77 & 73.33 \\
\hline & Haemorrhage & 23 & 21.90 \\
\hline & Thrombosis & 01 & 00.95 \\
\hline \multirow[t]{5}{*}{2.} & \multicolumn{3}{|c|}{ Degenerative and necrotic changes } \\
\hline & Cloudy Swelling & 25 & 23.81 \\
\hline & Hydropic Degeneration & 19 & 18.09 \\
\hline & Fatty change & 09 & 08.57 \\
\hline & Coagulative necrosis & 19 & 18.09 \\
\hline \multirow[t]{6}{*}{3.} & \multicolumn{3}{|l|}{ Inflammatory conditions } \\
\hline & Acute hepatitis & & \\
\hline & a. Focal acute hepatitis & 15 & 14.28 \\
\hline & b. Multifocal acute hepatitis & 06 & 05.71 \\
\hline & Chronic hepatitis & 04 & 03.81 \\
\hline & Abscess & 01 & 00.95 \\
\hline \multirow[t]{2}{*}{4.} & \multicolumn{3}{|l|}{ Other condition } \\
\hline & Bile duct hyperplasia & 07 & 06.67 \\
\hline
\end{tabular}




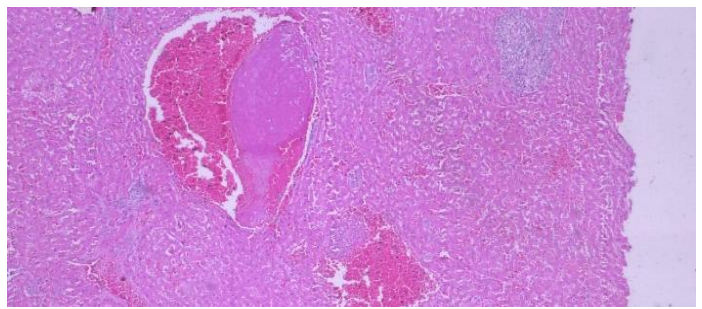

Fig 1: Microphotograph of liver, showing thrombosis, red blood cells alternating with fibrin in the central vein along with focal hepatitis, congestion and haemorrhagic changes. H\&E $\times 40$

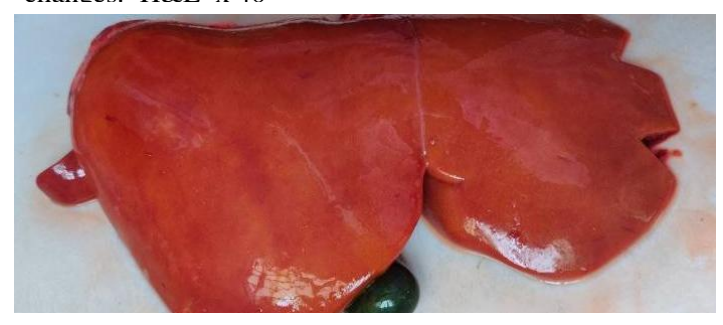

Fig 3: Gross photograph of liver showing fatty change, distended gall bladder, enlarged liver with rounded border.

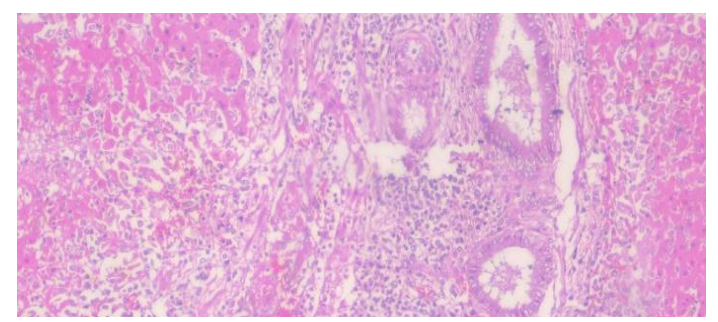

Fig 5:Microphotograph of liver showing acute multifocal hepatitis, infiltration of inflammatory cells, and bile duct hyperplasia.H\&E $\times 100$

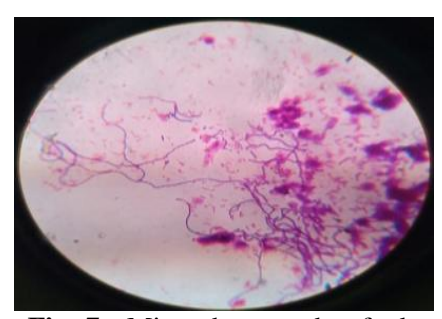

Fig 7: Microphotograph of abscess smear showing Fusobacterium spp., that are Gram negative, with long and short rods sometimes showing curling and tangling.Gram's x 1000

Fusobacterium spp. was demonstrated from smear of abscess (Fig. 7), which was supported by Khaled-Al-Qudahand Ahmad (2003). Bacteria can reach liver via a number of different routes and induce the formation of abscesses that includes portal vein, the umbilical vein in neonants, generalized

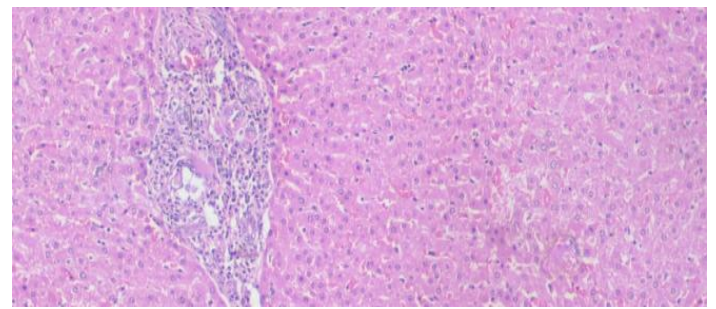

Fig 2:Microphotograph of liver showing hydropic degeneration, enlarged hepatocytes with presence of small clear, pale multiple vacuoles, cloudy swelling acute portal hepatitis.H\&E $\times 100$

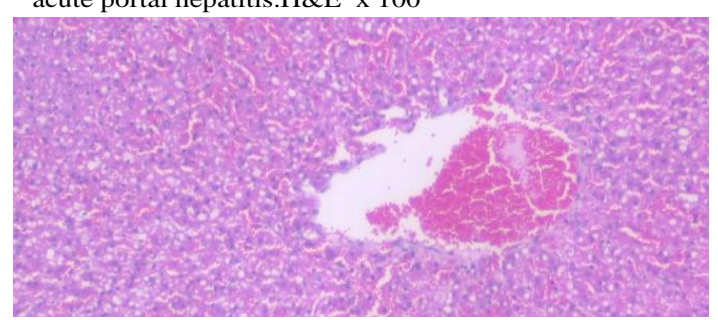

Fig 4:Microphotograph of liver showing fatty change, presence of small clear fat globules in the cytoplasm of hepatocytes along with mild degeneration and congestion of central vein.H\&E x 200

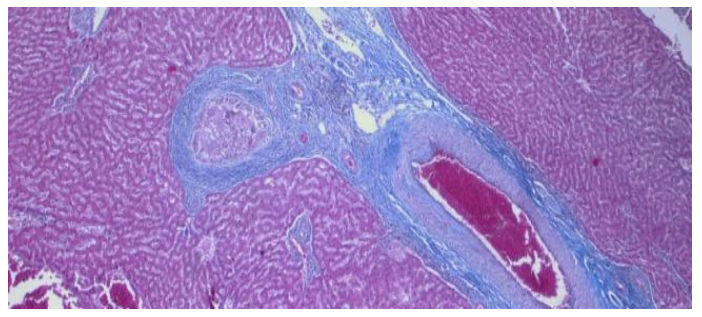

Fig 6: Microphotograph of liver showing chronic hepatitis. showing, the connective tissue (blue) proliferation around portal tract and congestion of hepatic vessels. MST x 40

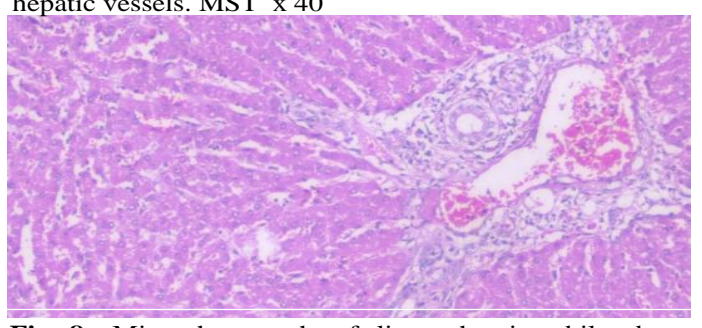

Fig 8: Microphotograph of liver showing bile duct hyperplasia, severe destruction in the liver tissue including necrosis and proliferation of numerous small to large sized bile ducts. Also note portal congestion and mild inflammation. H \& E 100

bacteremia reaching the liver via the hepatic artery, an ascending infection of the biliary system by parasitic migration as a direct extension of an inflammatory process from tissues such as the reticulum immediately adjacent to the liver (Khaled-Al-Qudah and Ahmad, 2003). Grossly, liver showed large 
abscess, which had a connecting tract with a hard dried onion patterned mass at right abdominal region in sheep. Microscopically, abscess had a thick cellular detritus in the center surrounded by cellular infiltration consisting mainly lymphocytes with few polymorphs at the inner margin of the abscesses and surrounded by a thick fibrous tissue. Similar to the present study, single to multiple abscesses were recorded in liver by earlier researchers (Sonawane et al., 2016; Al-Taee et al., 2017).

\section{Other conditions}

Bile duct hyperplasia was observed in 6.67 per cent of cases. Khan et al., (2015) recorded a higher occurrence at 19.70 per cent. Microscopically, it is associated with severe destruction of the liver tissue including inflammation, atrophy, necrosis, fibrosis and hyperplasia of the bile ducts (Fig. 8). The lesion of biliary hyperplasia has been described by many workers to be association with cirrhosis (Cherian et al., 2010 and Khan et al., 2015). However, in the present work, lesions of bile duct hyperplasia were seen along with acute and chronic hepatitis.

\section{References}

Abed, F. M., 2012. A pathological study of lesions in the liver of sheep in abattoir of Kirkuk province. Europ. J. Appl. Sci.,4(4): 140-145

Al-Nassir, H. S., 2014. A surveillance study on condemnation of ruminant's livers and lungs due to common disease conditions in Kerbala abattoirs. Kufa J. Vet. Med. Sci., 5(1): 22-30

Al-Taee, E. H., Al-Naimi, R. A., Znad, K. H. and Al-Tamimi, A. A., 2017. Study the histopathological changes and bacteriological causes of natural infection of the livers in sheep at Diyala Province. Diyala J. Pure Sci., 13(4): 12-22

Arafat, M. S. H., Aktar, M., Rashid, M., Kabir,
M. E., Ruba, T., Alam, K. J., Hossain, M. I., and Hossain, M. M., 2015. Abattoir survey on the liver diseases of sheep in Mymensingh municipality area in Bangladesh. Vet. Med. Rec., 1(2): 105110

Bhavyapriyanka, P., 2017. Pathological studies on spontaneous lesions in slaughtered sheep. M.V.Sc. thesis, Sri Venkateswara Veterinary University Tirupati, India

Cherian, S., Placid, E. D'souza., Renuka, Prasad, C., and Suguna, Rao, 2010. Histopathological observations in ovine schistosomosis. J. Vet. Parasitol., 24(2): 129-131

Dharvadiya, N. S., Joshi, D. V., Patel, B. J., Raval, S. H. and Patel, J. G., 2014. Pathomorphological studies on spontaneously occurring hepatic lesions in sheep (Ovis aries). Rumin. Sci., 3(1): 41-43

FAOSTAT: Food and Agriculture Organization Statistics., 2014. Statistical data base of livestock. Rome, Italy

Gezu, M. and Addis, M., 2014. Causes of liver and lung condemnation among apparently healthy slaughtered sheep and goats at Luna abattoir, Modjo, Ethiopia. Adv. Biol. Res., 8: 251-6

Hamond, C., Silveira, C. S., Buroni, F., Suanes, A., Nieves, C., Salaberry, X., Aráoz, V., Costa, R. A., Rivero, R., Giannitti, F. and Zarantonelli, L., 2019. Leptospira interrogans serogroup Pomona serovar Kennewicki infection in two sheep flocks with acute leptospirosis in Uruguay. Transbound. Emerg. Dis., 1: 5-8

Hassanein, K. M., Sayed, M. M. and Hassan, A. M., 2017. Pathological and biochemical studies on enterotoxemia in sheep. Comp. Clin. Path., 26(3): 513-518

Jubb, K. V. F., Kennedy, P. C. and Palmer, N., 2007. Pathology of domestic animals. Edn. $5^{\text {th }}$, Academic Press, New York and Landon., pp 259-447

Khaled-Al-Qudah, and Al-Majali, Ahmad., 2003. Bacteriologic studies of liver abscesses of Awassi sheep in Jordan. Small Rumin. Res., 47(3): 249-253 
Khan, S. A., Muhammad, S., Khan, M. M. and Khan, M. T., 2015. Study on the prevalence and gross pathology of liver fluke infestation in sheep in and around Quetta District, Pakistan. Adv. Anim. Vet. Sci., 3(3): 151-155

Kumar, J., Sonawane, G. G., Tripathi, B. N., Meena, A. S., Singh, F. and Dixit, S. K., 2013. Bilateral mixed bacterial pyelonephritis in a crossbred sheep. Indian J. Small Rumin., 19: 61-6

Luna, L. G., 1968. Manual of histologic staining methods of the armed forces institute of pathology. 3 Mc Graw Hill book Co, New York, U. S. A., pp 1-92

Mason, G. L. and Madden, D. J., 2007. Performing the field necropsy examination. Vet. Clin. North Am., 23(3): 503-526

OMOTAINSE, S.O. andANOSA V.O., 2009. comparative histopathology of lymph nodes, spleen, kidney and liver in experimental trypanosomiasis. Onderstepoort J. Vet. Res., 76: 377-383

Ozmaie, S., Akbari, G., Asghari, A., Sakha, M. and Mortazavi, P., 2013. Experimental oleander (Nerium oleander) poisoning in sheep: Serum biochemical changes and pathological study. Ann. Biol. Res., 4(1): 194-198

Regassa, A., Moje, N., Megersa, B., Beyene, D., Sheferaw, D., Debela, E., Abunna, F. and Skjerve, E., 2013. Major causes of organs and carcass condemnation in small ruminants slaughtered at Luna
Export Abattoir, Oromia Regional State, Ethiopia. Prev. Vet. Med., 110(2): 139148

Sarkar, S., 1998. Pathology of ovine liver. Indian J. Vet. Pathol., 22(1): 79

Sonawane, G. G., Kumar, J. and Sisodia, S. L., 2016. Etio-pathological study of multiple hepatic abscesses in a goat. Indian J. Vet. Pathol., 40(3): 257-260

Tafti, A. K., Nazifi, S., Rajaian, H., Sepehrimanesh, M., Poorbaghi, S. L. and Mohtarami, S., 2008. Pathological changes associated with experimental salinomycin toxicosis in sheep. Comp. Clin. Pathol., 17(4): 255-258

Tehrani, A., Javanbakht, J., Hassan, Mamh., Zamani, M., Rajabian, M., Akbari, H. and Shafe, R., 2012. Histopathological and bacteriological study on hepatic abscesses of herrik sheep. J. Med. Microb. Diagn., 1(4): 32-41

Thannon, H. B., 2018. pulmonary and hepatic lesions in slaughtered sheep in Mosul city. Tikrit. J. Pure Sci., 22(6): 25-33

Verma, D., 2014. Enteropathology in goats with special reference to enterotoxaemia. M.V.Sc. thesis, Nanaji Deshmukh Viterinary Science University, Jabalpur

Zangana, I. K. and Aziz, K. J., 2012. Prevalence and pathological study of schistosomiasis in sheep in Akra/Dohuk province, northern Iraq. Iraq J. Vet. Sci., 26: 125130.

\section{How to cite this article:}

Kiran, H. J., G. M. Jayaramu, B. Kavitha Rani, S. S. Manjunatha and Satish, E. S. 2020. Pathomorphological Studies on Hepatic Disorders in Sheep. Int.J.Curr.Microbiol.App.Sci. 9(11): 294-300. doi: https://doi.org/10.20546/ijcmas.2020.911.035 